\title{
Electrophysiologic changes after intravitreal ranibizumab injection for the treatment of choroidal neovascular membrane (CNVM)
}

This article was published in the following Dove Press journal:

Clinical Ophthalmology

4 May 2011

Number of times this article has been viewed

\section{Patama Bhurayanontachai Mansing Ratanasukon Pichai Jirarattanasopa \\ Retina Unit, Department of Ophthalmology, Faculty of Medicine, Prince of Songkla University, Hat Yai, Songkhla, Thailand}

Purpose: To determine the pattern of electroretinographic change after an intravitreal ranibizumab (Lucentis ${ }^{\circledR}$ ) injection for the treatment of choroidal neovascular membrane (CNVM).

Patients and methods: A prospective interventional case series of patients treated by intravitreal ranibizumab injection. Best corrected visual acuity, optical coherence tomography (OCT), and multifocal electroretinography (mfERG) were assessed prior to treatment, and 2 weeks, 1 and 3 months after treatment. Primary outcome was the functional change in amplitude and implicit time by mfERG and secondary outcome was the structural change in macular thickness by optical coherence tomography (OCT).

Results: Twenty-six eyes from 25 consecutive patients were enrolled. At 3 months after treatment, the mean visual acuity (VA) improved from 1.06 to $0.84 \log$ MAR $(P=0.034)$ and the mean macular thickness decreased from 389.7 to 264.4 microns $(P=0.003)$. The mean implicit time of the central zone showed an improvement at 3 months after treatment when compared with the response at baseline $(P=0.024)$ and at 1 month $(P=0.013)$ but the mean amplitude showed no significant change. In subgroup analysis, the eyes with initial visual acuity (VA) $\geq 20 / 200$ had a significant improvement in mean implicit time of the peripheral zone at 2 weeks after treatment $(P=0.028)$. The OCT revealed a significant decrease $(P<0.003)$ in macular thickness at 1 and 3 months postoperatively.

Conclusion: The mean implicit time of the central zone improved significantly at 3 months after treatment, whereas the mean amplitude showed no significant change. The macular thickness decreased significantly after the treatment, while VA improved to a lesser extent.

Keywords: choroidal neovascular membrane (CNVM), intravitreal injection, multifocal electroretinography (mfERG), optical coherence tomography (OCT), ranibizumab

\section{Introduction}

Choroidal neovascular membrane (CNVM) is an abnormal vascular proliferation from beneath the retina and is related to many different underlying retinal conditions, especially age-related macular degeneration. Over the past few years, the introduction of anti-vascular endothelial growth factor (anti-VEGF) drugs has changed the way CNVM is treated. Ranibizumab is one of the novel anti-VEGF drugs that has been proved to be efficient and safe for intravitreal injection. ${ }^{1}$ However, there are few reports of retinal function changes by electroretinography (ERG) after treatment with antiVEGF agents. ${ }^{2-4}$ The multifocal ERG allows the simultaneous derivation of 103 local ERG signals in a central visual field of about $50-60^{\circ}$ diameter around the fovea. The impairment of macular function due to regional disorders in the outer retinal layers
Correspondence: Patama Bhurayanontachai Retina Unit, Department of Ophthalmology, Faculty of Medicine, Prince of Songkla University, Hat Yai, Songkhla, 90110 , Thailand Tel +6674451380

Fax +6674429619

Email tpatama@hotmail.com 
can be described in detail by this technique, which allows the functional mapping of the retina. ${ }^{5}$

The objective of the study was to determine the pattern of ERG change after an intravitreal ranibizumab injection, for patients with CNVM.

\section{Materials and methods}

The study was a prospective consecutive interventional study, under the approval of the Ethics Committee of Songklanagarind Hospital, Songkhla, Thailand. Patients were recruited from August 2007 to August 2008. The patients received a $0.5 \mathrm{mg}$ intravitreal ranibizumab monotherapy for any type of CNVM confirmed by fundus fluorescein angiography (FFA). The method relies upon the results of the superiority of ranibizumab to photodynamic therapy (PDT) in all subgroups evaluated from the ANCHOR study. ${ }^{6}$

The informed consents of all subjects who participated in the study were obtained after the nature of the procedure and possible discomforts and risks had been fully explained. All patients received their first intravitreal injection in an operating room under an aseptic preparation technique within 8 days after an angiographic study. Ranibizumab $0.5 \mathrm{mg}$ (Lucentis $^{\circledR}$; Novartis Pharma AG, Basel, Switzerland) was injected intravitreally at $4.0 \mathrm{~mm}$ from the limbus in phakic eyes and at $3.5 \mathrm{~mm}$ in pseudophakic eyes. The patients were then instructed to take an antibiotic for 1 week and were scheduled for further postoperative visits at 2 weeks, 1 month, and 3 months after the injection. Retreatment with an interval of a month was considered if the retinal condition was still active. Any post-operative complications such as prolonged inflammation, endophthalmitis and rapid cataract progression were recorded.

The primary outcome was a change in functional response of the signal amplitude or response density and the implicit time or P1 latency which were shown by 103 numeric values in a multifocal ERG (mfERG). The ERG (VERIS Science 6.0.7 d15, EDI, Redwood City, CA, USA), as well as the patients, were prepared following the International Society for Clinical Electrophysiology of Vision (ISCEV) guidelines. ${ }^{7}$ Each patient was light adapted for at least 15 minutes with room lights or at least two hours after an exposure to a bright light. The patients' pupils were fully dilated before the test to maximize the retinal illumination. The mfERG response signals were classified into 3 zones for analysis of localized alteration (Figure 1). A central zone represented signals from 7 central hexagons, a mid zone represented a middle ring of 30 hexagons, and a peripheral zone represented 66 signals from hexagons in the peripheral macular area.

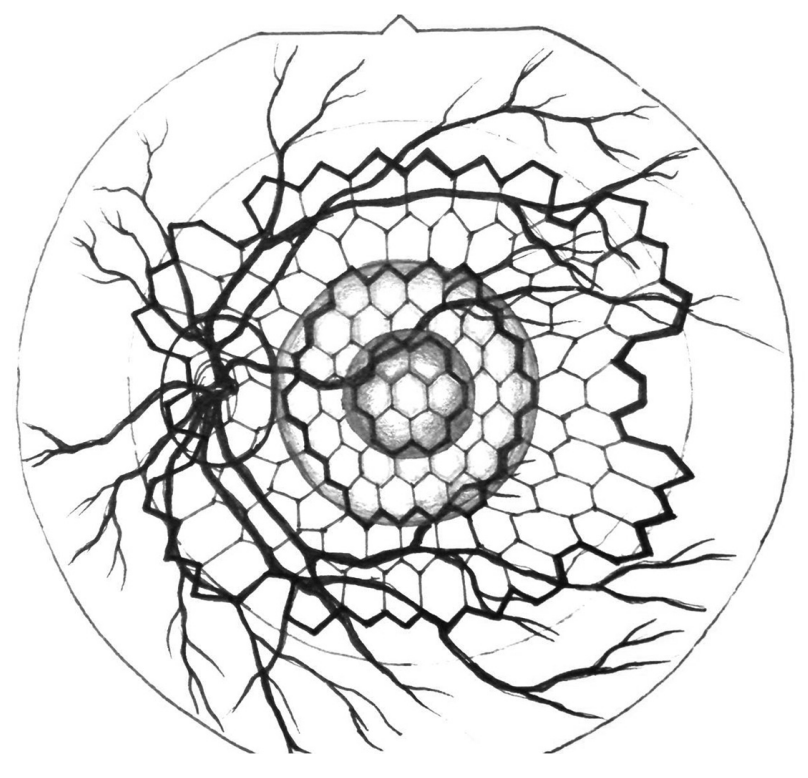

Figure I A schematic illustration of topographical mfERG map.

A structural change in central macular thickness was considered as a secondary outcome. The thickness was measured by optical coherence tomography (OCT; Stratus OCT III, v.4, Zeiss, Oberkochen, Germany). Fundus angiography was performed after informed consent was provided and the angiographic photos were captured by a Kowa VX-10i fundus camera (Kowa Co Ltd, Tokyo, Japan). Eyes that had been previously treated by laser photocoagulation, photodynamic therapy, or intravitreal injection of any therapeutic agent were excluded from the study.

The program SPSS version 11.5 was used for data processing. Statistical analyses included Student's $t$-test for parametric data, Mann-Whitney $U$ test for non-parametric data and Pearson's correlation coefficient for a measure of association between two variables. A statistical difference was considered significant when the $P$-value was $\leq 0.05$.

\section{Results}

The baseline demographic data are shown in Table 1. Twenty-seven eyes from 26 consecutive patients were initially enrolled in the study but 1 patient (1 eye) was excluded at the end of the study due to a protocol violation. The average age of the remaining 25 patients was $66.5 \pm 9.3$ years. Seventeen patients were non-smokers, 3 were occasional smoking males, and 5 were prolonged ( $>1$ year) ex-smoking males. The mean baseline best corrected visual acuity (VA) was $1.06 \pm 0.51 \log$ MAR (logarithm of Minimum Angle of Resolution). Pre-operative FFA revealed 6 eyes (23.1\%) with predominantly classic CNVM, 1 eye $(3.8 \%)$ with minimally classic CNVM, and 19 eyes (73.1\%) with 
Table I Baseline clinical characteristics of the patients

\begin{tabular}{|c|c|}
\hline Characteristics & \\
\hline Mean age in years (range) $(n=25)$ & $66.5 \pm 9.3(49-83)$ \\
\hline No. (\%) of female patients & $16(64)$ \\
\hline \multicolumn{2}{|l|}{ No. (\%) of patients with systemic disease } \\
\hline No underlying disease & $9(36)$ \\
\hline Diabetes mellitus & $2(8)$ \\
\hline Hypertension & $8(32)$ \\
\hline Diabetes mellitus + hypertension & I (4) \\
\hline Hypertension + other & $2(8)$ \\
\hline Others & $2(8)$ \\
\hline No. $(\%)$ of right eye $(n=26)$ & $12(46.2)$ \\
\hline \multicolumn{2}{|l|}{ No. (\%) of lens status } \\
\hline Phakic & $19(73.1)$ \\
\hline Pseudophakic & $7(26.9)$ \\
\hline \multicolumn{2}{|l|}{ No. (\%) of CNVM types } \\
\hline Predominantly classic & $6(23.1)$ \\
\hline Minimally classic & I (3.8) \\
\hline Occult & $19(73.1)$ \\
\hline $\begin{array}{l}\text { Mean duration of visual symptom } \\
\text { in weeks (range) }\end{array}$ & $19.3 \pm 30.2(0.5-120)$ \\
\hline Mean VA in logMAR (range) & $1.06 \pm 0.5 \mid(0.3-1.7)$ \\
\hline Mean IOP in mmHg (range) & $12.5 \pm 2.5(7.2-18.0)$ \\
\hline Mean macular thickness in microns (range) & $389.7 \pm 151.3(177-724)$ \\
\hline
\end{tabular}

Abbreviations: CNVM, choroidal neovascularization membrane; VA, visual acuity logMAR, logarithm of Minimum Angle of Resolution; IOP, intraocular pressure; $\mathrm{mmHg}$, millimeters of mercury.

occult CNVM. The greatest linear diameter (GLD) of the eyes with predominantly classic CNVM varied from 878 to 4,944 microns (mean 2,453.67 $\pm 1,454.81$ ).

The studied eyes were divided into 2 groups post hoc; 14 of 26 eyes (54\%) in subgroup-A with initial VA $>1$ $\log$ MAR $(\mathrm{VA}<20 / 200)$ and 12 eyes $(46 \%)$ in subgroup-B with initial $\mathrm{VA} \leq 1 \log \mathrm{MAR}$ (VA $\geq 20 / 200$ ). The average age in subgroup-A was 69.9 years and in subgroup-B was 62.4 years $(P=0.035)$. The preoperative mean macular thickness and intraocular pressure (IOP) were insignificantly different between subgroups ( $P=0.451$ and $P=0.754$ respectively).

Twelve eyes received only one injection of intravitreal ranibizumab. Two eyes received their re-treatment once at a month apart. Eleven eyes received their re-treatment twice, in which case the second and the third ranibizumab injections were performed at one and two months after an initial treatment. A patient who had bilateral active disease began her second eye treatment a month later after she had finished the third injection for the first eye. There was neither a serious postoperative complication nor a need for cataract surgery reported within 6 months after an intravitreal injection. One patient had chest discomfort and chest muscle twitching 6 hours after his second intravitreal injection that was relieved by medications. He refused a third injection.

The mean baseline IOP was $12.5 \pm 2.5 \mathrm{mmHg}$. The mean IOPs at 2 weeks, 1 month, and 3 months after treatment were $12.6,12.3$, and $10.9 \mathrm{mmHg}$, respectively. A statistically significant difference in IOP change was seen at the third month $(P=0.779,0.922$, and 0.011 , respectively).

\section{Primary outcome: functional change}

The mean values of baseline amplitude or response density $\left(\mathrm{nV} / \mathrm{deg}^{2}\right)$ and implicit time (mseconds) of all patients and of both subgroups are shown in Table 2. A significant difference between subgroups appeared only in the amplitude of the mid zone. The overall mean implicit time of the central zone clearly demonstrated an improvement at 3 months after treatment when compared with the response at baseline $(P=0.024)$ and at 1 month $(P=0.013)$. There was no significant change in mean amplitude between visits, compared to the baseline value. In a subgroup analysis (Figure 2), the significant change in subgroup-A was the amplitude in the mid zone at 1 month after treatment $(P=0.033)$. Only the mean implicit time of the peripheral zone in subgroup-B clearly showed an improvement at 2 weeks after treatment $(P=0.028)$.

A subgroup comparison showed that the postoperative mean amplitude in the central and mid zones of subgroup-B

Table 2 Baseline amplitude and implicit time

\begin{tabular}{|c|c|c|c|c|c|c|c|c|c|c|}
\hline & \multirow[t]{2}{*}{$\mathbf{n}$} & \multicolumn{3}{|c|}{ Peripheral zone (66) } & \multicolumn{3}{|c|}{ Mid zone (30) } & \multicolumn{3}{|c|}{ Central zone (7) } \\
\hline & & Mean & SD & $P$-value & Mean & SD & $P$-value & Mean & SD & $P$-value \\
\hline \multicolumn{11}{|l|}{ Amplitude } \\
\hline Overall & 26 & 2.859 & 1.085 & & 3.475 & $1.51 \mathrm{I}$ & & 5.028 & 2.618 & \\
\hline Subgroup-A & 14 & 2.570 & 1.160 & 0.198 & 2.827 & 1.313 & 0.024 & 4.586 & 3.104 & 0.143 \\
\hline Subgroup-B & 12 & 3.196 & 0.925 & & 4.230 & 1.413 & & 5.543 & 1.910 & \\
\hline \multicolumn{11}{|c|}{ Implicit time } \\
\hline Overall & 26 & 31.621 & 3.563 & & 32.819 & 7.567 & & 34.327 & 7.010 & \\
\hline Subgroup-A & 14 & 31.907 & 3.119 & 0.700 & 34.656 & 4.350 & 0.328 & 35.060 & 5.286 & 0.797 \\
\hline Subgroup-B & 12 & 31.287 & 4.140 & & 30.676 & 9.924 & & 33.427 & 8.947 & \\
\hline
\end{tabular}

Notes: Subgroup-A: initial VA $<20 / 200$; Subgroup-B: initial VA $\geq 20 / 200$.

Abbreviation: SD, standard deviation. 

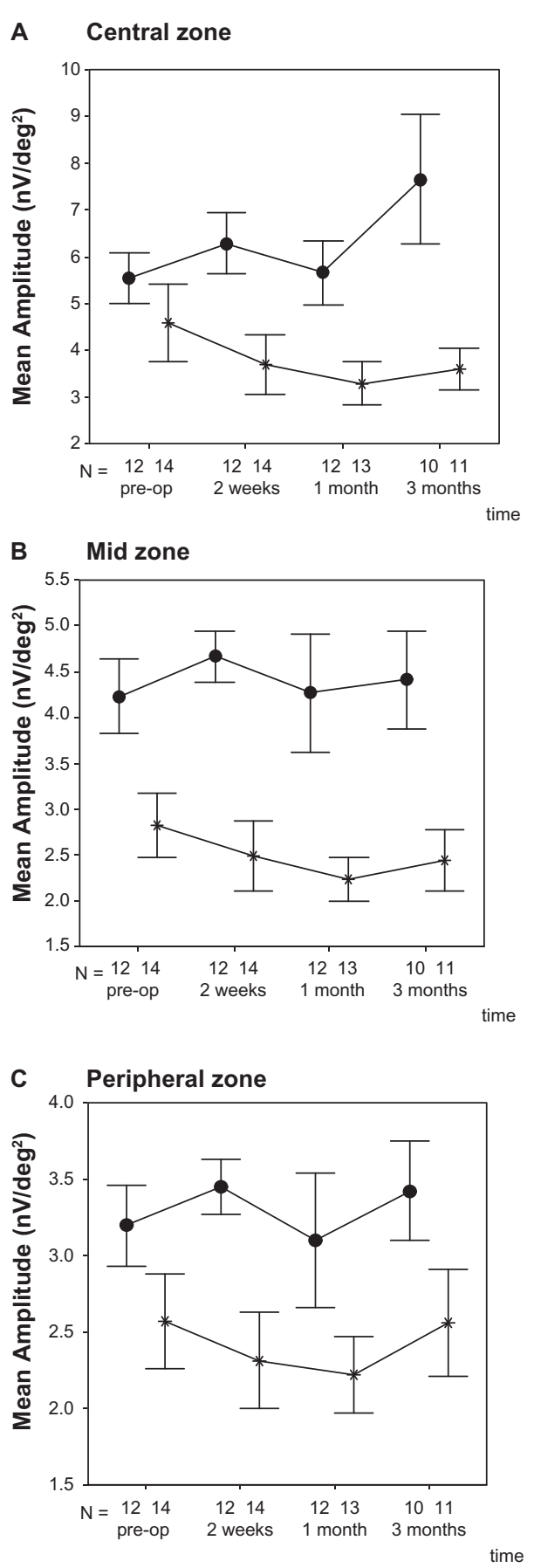

正 Sub group-A

Sub group-B
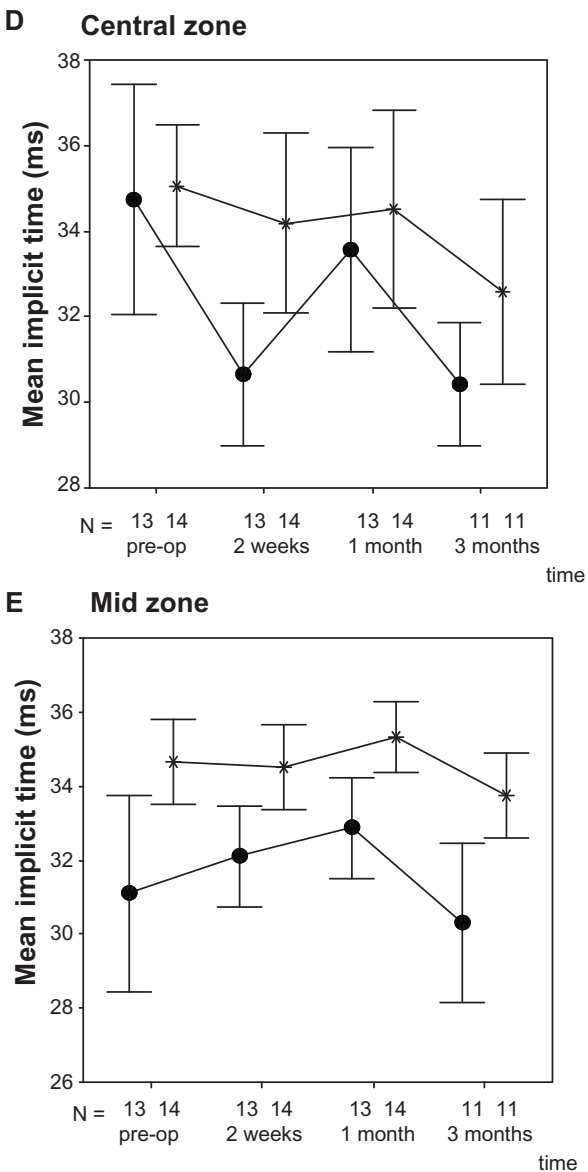

F Peripheral zone

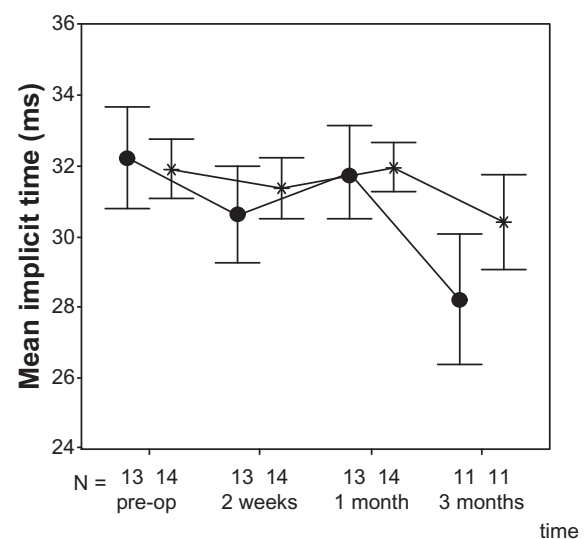

Figure 2 A-C) A change from baseline in nanovolts/deg ${ }^{2}$ of the mean amplitude over time in the central, mid, and peripheral zones. D-F) A change from baseline in milliseconds of the mean implicit time over time in the central, mid, and peripheral zones. The vertical line $=1$ standard error.

was better than that of subgroup-A at every follow-up visit $(P<0.02)$, whereas the mean implicit time had no significant difference between groups.

The mean postoperative VAs at 2 weeks, 1 month, and 3 months were $1.03,0.96$, and $0.84 \log$ MAR respectively. The significant difference of VA change was found at $1(P=0.021)$ and 3 months $(P=0.034)$ after treatment. The correlation analysis also found a significant reversed association between changes in amplitude and logMAR VA in the central and mid zones from 2 weeks onwards $(P<0.002)$, however, there was no correlation between the changes in implicit time and $\log$ MAR VA. 


\section{Secondary outcome: structural change}

The mean macular thicknesses were $389.7 \pm 151.3$ microns preoperatively, 290.0 microns at 1 month $(P<0.001)$ and 264.4 microns at 3 months $(P=0.003)$ postoperatively. Postoperative changes in macular thickness showed no significant difference among subgroups and had no correlation with either amplitude or implicit time.

\section{Discussion}

The present pilot study of an electrophysiologic response after an intravitreal ranibizumab injection included all ranges of initial VA in order to compare the pattern of electrophysiologic changes regardless of the visual outcome. Nevertheless, we performed a subgroup analysis to test the effect of disease severity, indicated by the level of vision, upon the response of mfERG.

The overall results showed a prominent improvement in the implicit time rather than the amplitude at 3 months after treatment, although there were a few significant postoperative differences within each subgroup. The patients in subgroup-B who had a better baseline VA were also significantly younger than the patients in subgroup-A $(P=0.035)$. The mean amplitude of subgroup-B was also better than that of subgroup-A on every visit, while the mean implicit time was not significantly different. This markedly showed a moderate to high statistical correlation of the signal amplitude with a patient's VA $(P<0.02)$. Thus, age may have an effect on an amplitude difference between groups, but from the result of this study it has no effect on the implicit time. Moreover, the improvement in the implicit time after the treatment indicates that the potency of functional recovery does not depend on age.

A significant reversed association between the amplitude and $\log$ MAR of VA indicates that the higher the rising amplitudes, the better the vision gains. This difference also shows that a patient's VA has a concordance with the signal amplitude or response density of mfERG, not the implicit time. However, the implicit time indicates an early functional improvement after the treatment. Gerth et $\mathrm{al}^{8}$ reported that the implicit times were found to be more sensitive in detecting abnormal retinal responses compared with the amplitude or response density. Thus, in the recovering retinal area a decrease in the implicit time may occur earlier than an increase in the amplitude.

After treatment, the OCT revealed a decrease in macular thickness by a strong significance $(P<0.003)$ while the mean VA had a lesser degree of significant improvement at the same time $(P<0.034)$. Our study shows similar results as in the bevacizumab and ranibizumab treatments from the previous reports. ${ }^{2-4}$ Therefore, anti-VEGF therapy can structurally reduce the macular edema, but may not fully recover the neuroretinal function. The next question is whether or not we can accelerate the improvement of vision. A method of vision restoration therapy (VRT) ${ }^{9}$ may be interesting because the early improvement area is mostly confined to the central and mid zones of the macula.

The limitation of this study is a lack of OCT data in some patients during an unfortunate period of machine malfunction. We not only recommend a future study with a longer follow-up period and a larger population, but also encourage the possibility of a careful visual rehabilitation trial of the watershed area by vision restoration therapy in the patients undergoing intravitreal ranibizumab treatments.

\section{Conclusion}

The mean implicit time of the central zone improved significantly at 3 months after treatment, whereas the mean amplitude had no significant change. There was a correlation between baseline VA and the amplitude of mfERG, but not the implicit time. The OCT also showed a decrease in macular thickness along with an improvement of VA after treatment. Continuous treatment with intravitreal ranibizumab monotherapy is required to evaluate the long-term results.

\section{Acknowledgment}

This study was supported by the Faculty of Medicine, Prince of Songkla University, Hat Yai, Songkhla, Thailand.

\section{Disclosure}

The authors have no commercial association or any conflict of interest in the drugs or machines mentioned in the study.

\section{References}

1. Lüke M, Januschowski K, Lüke J, et al. The effects of ranibizumab (Lucentis) on retinal function in isolated perfused vertebrate retina. Br J Ophthalmol. 2009;93(10):1396-1400.

2. Maturi RK, Bleau LA, Wilson DL. Electrophysiologic findings after intravitreal bevacizumab (Avastin) treatment. Retina. 2006;26(3): 270-274.

3. Moschos MM, Brouzas D, Apostolopoulos M, Koutsandrea C, Loukianou E, Moschos M. Intravitreal use of bevacizumab (Avastin) for choroidal neovascularization due to ARMD: a preliminary multifocalERG and OCT study. Doc Ophthalmol. 2007;114(1):37-44.

4. Feigl B, Greaves A, Brown B. Functional outcomes after multiple treatments with ranibizumab in neovascular age-related macular degeneration beyond visual acuity. Clin Ophthalmol. 2007;1(2): $167-175$.

5. Sutter EE, Tran D. The field topography of ERG components in man-I. The photopic luminance response. Vision Res. 1992;32(3):433-446. 
6. Kaiser PK, Brown DM, Zhang K, et al. Ranibizumab for predominantly classic neovascular age-related macular degeneration: Subgroup analysis of first-year ANCHOR results. Am J Ophthalmol. 2007;144(6): 850-857.

7. Marmor MF, Hood DC, Keating D, Kondo M, Seeliger MW, Miyake Y; International Society for Clinical Electrophysiology of Vision. Guidelines for basic multifocal electroretinography (mfERG). Doc Ophthalmol. 2003;106(2):105-115.
8. Gerth C, Hauser D, Delahunt PB, Morse LS, Werner JS. Assessment of multifocal electroretinogram abnormalities and their relation to morphologic characteristics in patients with large drusen. Arch Ophthalmol. 2003;121(10):1404-1414.

9. Jung CS, Bruce B, Newman NJ, Biousse V. Visual function in anterior ischemic optic neuropathy: Effect of vision restoration therapy (VRT) - A pilot study. J Neurol Sci. 2008;268(1-2):145-149.

\section{Publish your work in this journal}

Clinical Ophthalmology is an international, peer-reviewed journal covering all subspecialties within ophthalmology. Key topics include: Optometry; Visual science; Pharmacology and drug therapy in eye diseases; Basic Sciences; Primary and Secondary eye care; Patient Safety and Quality of Care Improvements. This journal is indexed on

\section{Dovepress}

PubMed Central and CAS, and is the official journal of The Society of Clinical Ophthalmology (SCO). The manuscript management system is completely online and includes a very quick and fair peer-review system, which is all easy to use. Visit http://www.dovepress.com/ testimonials.php to read real quotes from published authors. 